"Idiosyncratic volatility, investor sentiment, and returns of the GCC stock markets"

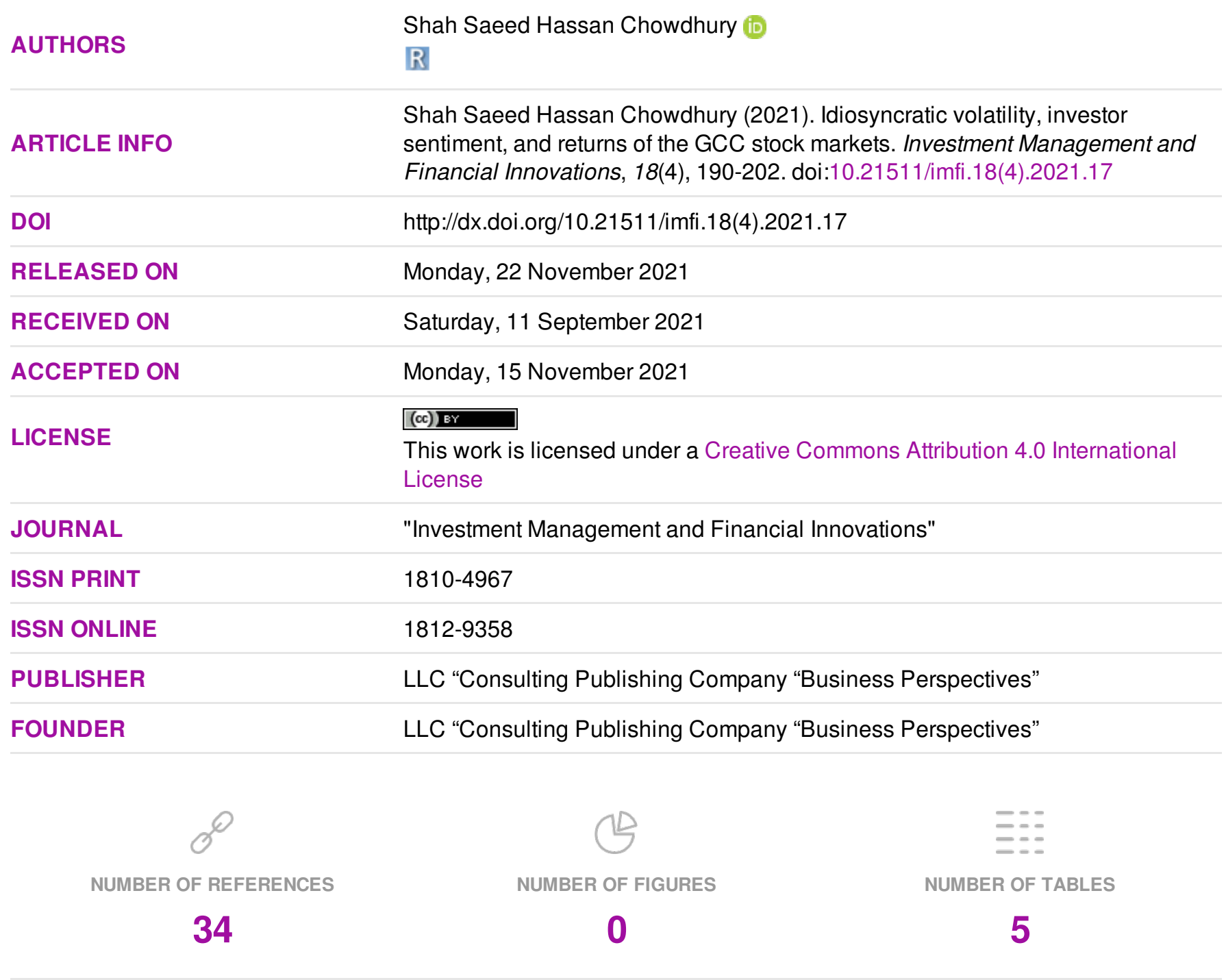

(C) The author(s) 2021. This publication is an open access article. 


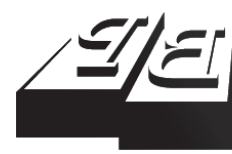

\section{BUSINESS PERSPECTIVES}

O

LLC "CPC "Business Perspectives"

Hryhorii Skovoroda lane, 10,

Sumy, 40022, Ukraine

www.businessperspectives.org
Received on: $11^{\text {th }}$ of September, 2021 Accepted on: $15^{\text {th }}$ of November, 2021 Published on: $22^{\text {nd }}$ of November, 2021

(c) Shah Saeed Hassan Chowdhury, 2021

Shah Saeed Hassan Chowdhury, Ph.D., Assistant Professor, Accounting and Finance Department, Prince Mohammad Bin Fahd University, Saudi Arabia.

Shah Saeed Hassan Chowdhury (Saudi Arabia)

\title{
IDIOSYNCRATIC VOLATILITY, INVESTOR SENTIMENT, AND RETURNS OF THE GCC STOCK MARKETS
}

\begin{abstract}
Standard finance theory suggests that idiosyncratic volatility should not influence stock returns. In reality, if investors are unable to achieve efficient diversification, such risk may affect stock returns. The purpose of the study is to examine the presence of idiosyncratic volatility and sentiment in the stock markets of the GCC (Gulf Cooperation Council) countries.

Monthly idiosyncratic volatility is estimated using the Fama-French three-factor model. A unified sentiment proxy for each market is created by employing Principal Component Analysis (PCA). Then, Ordinary Least Squares (OLS) regressions are applied. F-statistics, $t$-statistics, and adjusted $\mathrm{R}^{2} \mathrm{~s}$ are used to test the presence of idiosyncratic volatility and sentiment in the GCC markets.

Findings show that the effect of sentiment on stock returns is observed across all the GCC markets. Investor sentiment can weakly explain the effect of idiosyncratic volatility on stock returns. In general, investors do not price expected idiosyncratic volatility, and only the unexpected part of it affects stock returns.

Overall, the first implication for investors is that they must consider market sentiment to predict the cross-section of stock prices and should not completely ignore the influence of idiosyncratic volatility on stocks. Secondly, the implication for policymakers is that they should motivate companies to go public so that investors have more options to diversify their portfolios across different sectors.
\end{abstract}

\section{Keywords}

JEL Classification

\section{INTRODUCTION}

It is believed that investors are able to diversify their portfolios completely, and thus the market provides no premium for taking idiosyncratic risk. However, reality is different, and findings of many previous studies suggest that investors do not achieve efficient diversification for their portfolios, since they hold only few assets. Obviously, in the case of under-diversification, investors may want rewards for having idiosyncratic volatility (hereafter, IV) in their portfolios. Thus, IV is expected to play a vital role in influencing the risk-return relationship in real-life situation.

An important factor for the pricing of idiosyncratic risk is the presence of individual traders, especially in emerging markets. Unpredictable behaviors of individual traders generate risk in the asset prices, which creates obstacles for rational arbitragers to bet against them. When a market is dominated by individual traders, even smart investors have to ask for risk premium for taking such risk. The presence of idiosyncratic risk can also be linked to the phenomenon of investor sentiment. Overall, as sentiment may contribute to IV prevailing in the market while the influence of IV on returns may also be present, it is a good research idea to consider separating the impact of sentiment from the IV-stock return relationship. 
Evidence found in developed markets (discussed in the literature review section) may differ in emerging or frontier markets due to lack of transparency, illiquidity, lack of corporate governance, political influence, and weak surveillance by capital market monitoring/regulatory authority in these markets. GCC stock market consists of seven individual markets such as Abu Dhabi, Bahrain, Dubai, Kuwait, Oman, Qatar, and Saudi Arabia. As of June 2020, this region was an attractive market with the market capitalization of about US\$2.69 trillion. Only few studies have focused on this regional market, despite its ability to attract global portfolio investors. Global investors obviously need to know more about these largely unexplored regional markets.

\section{LITERATURE REVIEW}

Findings of many studies, such as Barber and Odean (2000), Benartzi and Thaler (2001), Campbell et al. (2001), and Goetzmann and Kumar (2008), suggest that investors do not achieve efficient diversification for their portfolios, since they hold only few assets. This phenomenon contributes to the pricing of idiosyncratic volatility. The relationship between IV and stock returns of developed markets has been observed in many previous studies (Ang et al., 2006; Bali \& Cakici, 2008; Chua et al., 2010; Cotter et al., 2015). Some papers find a positive relationship between IV and future returns (Chichernea et al., 2015; Fu, 2009), whereas some find a negative relationship (Ang et al., 2006, 2009; Cotter et al., 2015). Some of the studies report an insignificant IV-returns relationship (Bali \& Cakici, 2008; Boyer et al., 2010).

The studies on non-U.S. markets also report the presence of the impact of IV. In a study on the G-7 countries, Guo and Savickas (2008) show a significant IV-return relationship for the U.K. market. Moreover, the U.S. IV negatively predicts other mature stock market returns. Ang et al. (2009) report a negative relationship between IV and returns for non-U.S. mature markets. For the Australian stock market, the findings of Gharghori et al. (2011) and Zhong and Gray (2016) report an inverse relationship between IV and returns.

Emerging markets also show the ability of IV to predict future stock returns. In the absence of quality information in these markets, investors cannot confidently rely on available information, ultimately resulting in more dependence on firm-specific risk. Thus, a significant part of IV goes undetected, especially when portfolios are not well-diversified. Some studies show that most emerging stocks experienced a noticeable increase in IV during the 1990s (Li et al., 2004; Kearney \& Poti, 2008). Angelides (2010) suggests that both firm-specific risk and market risk are important to predict stock returns of emerging markets. Currently, India and China are two highly growing emerging markets. Nartea et al. (2013) present the evidence of a negative effect of IV on stock returns in China. Kumari et al. (2017) show how firm-specific characteristics can explain the idiosyncratic volatility of non-financial firms in the Indian stock market. For this market, Aziz and Ansari (2017) suggest that there is a positive association between IV and stock returns, and that this relationship is sensitive to firm characteristics such as firm size. These findings contrast with that of Nartea et al. (2011), who do not find any presence of impact of IV for four Southeast Asian markets, namely, Indonesia, Malaysia, Thailand, and the Philippines.

IV may also be related to firm-specific characteristics such as firm size, industry, life cycle and BV/MV ratio. Some studies also focus on other possible reasons for such phenomenon. Pastor and Veronesi (2003) show that the impact of idiosyncratic volatility on returns changes as a firm gets old. Young firms usually go through a period of volatile profitability, making themselves more susceptible to IV. Chen and Petkova (2012) note that the choice of asset-pricing models plays an important role in estimating IV. High (low) idiosyncratic risk portfolios based on the Fama-French (1993) model have positive (negative) contributions to shocks to average stock volatility and consequently result in lower (higher) expected returns.

Liu et al. (2019) report that there is a significantly positive relationship between idiosyn- 
cratic volatility and future Chinese stock returns. Moreover, according to them, the power of idiosyncratic volatility depends on how this volatility measure is constructed. Using recent U.S. data, Qadan et al. (2019) find that the aggregate market volatility risk - measured by the VIX - plays a strong role on the IV-returns relationship. An increase (decrease) in the VIX index is followed by a negative (positive) relationship between IV and future returns. Sharma and Kumar (2014) show that IV positively influences the cross-section of Indian stock returns. After adjusting for unexpected IV, the inter-temporal dependence between expected IV and expected returns is found to be positive. That is, when investors perceive firm-specific risk of a firm, this information pushes its stock prices upward.

There are only few studies on the effect of IV on the GCC markets. Only few papers have so far discussed the issue of IV for the GCC markets. Bley and Saad (2012) report a significantly negative relationship for Saudi Arabia and Qatar. However, they report an absence of such a relationship for Kuwait and Abu Dhabi. Ali (2016) finds that value premium for Kuwait and Oman markets can be explained by idiosyncratic risk. These findings, obviously, rationalize the possibility of the strong impact of IV on emerging markets such as the GCC, which are believed to have a noisy dissemination of information through less-informed, retail traders.

Baker and Wurgler (2007) give a strong evidence of the role of investor sentiment on stock prices. Sharmin (2019) is the first study to provide a detailed report on the presence of sentiment in all the individual GCC stock markets. She gives the evidence of a robust presence of the sentiment-return association in all the GCC markets and suggests for the inclusion of sentiment in the asset valuation models for these markets. Chowdhury et al. (2021) report similar findings for another emerging market - Bangladesh. Chowdhury (2020) considers only the spillover of sentiment between the individual GCC markets. He reports that the Saudi and the UAE markets are well integrated from the view point of sentiment, and thus any change in one of these markets is likely to spillover to other. Hence, investor sentiment cannot be ignored. There are only few idiosyncratic volatility-related studies on the GCC markets. None of them, in fact, considers the influence of sentiment on the volatility-return relationship. Thus, a study on the presence of idiosyncratic volatility and sentiment in the stock markets of the GCC countries has the potential to contribute significantly to the extant literature.

\section{OBJECTIVES OF THE STUDY}

The relevant findings of similar studies on developed markets, the recent strong performance of emerging markets, the emergence of psychological aspects of investors, and the idiosyncrasies of these markets have resurrected the interest of academics, investors, policy makers and media to investigate these markets in detail. In this backdrop, this study provides following three research objectives:

(i) To detect the relationship between IV and the returns of individual markets and size-sorted portfolios in the GCC region;

(ii) To distinguish the impact of expected and unexpected IV on market and size portfolio returns; and

(iii) To recognize the ability of market sentiment to explain the IV-return relationship, if any.

\section{DATA AND METHODOLOGY}

\subsection{Data}

The sample of this study consists of monthly return indices of 648 firms listed on stock exchanges of Abu Dhabi, Bahrain, Dubai, Kuwait, Oman, Qatar, and Saudi Arabia. This study covers the period January 2004 through March 2019. Only Oman has a slightly shorter duration of data - November 2005 through March 2019. Returns are defined as the log difference of two monthly consecutive stock return indices times 100 . Stocks with data of less than 30 months have been dropped from the 
study. To calculate SMB (Small Minus Big) and SML (High Minus Low) returns, market value, $\mathrm{BV} / \mathrm{MV}$, and return index data for firms are also collected from DataStream. ${ }^{1}$

\subsection{Construction of size portfolios}

Size portfolios are constructed using the market cap of individual stocks (as a measure of size) on the last trading day of each December. That is, portfolios are rebalanced annually. All the firms are sorted into quartiles based on respective size (market capitalization). For all the markets, stocks are sorted as smallest, small, large and largest size ones. The use of only four size portfolios is influenced by the presence of a small number of firms in these markets.

\subsection{Realized idiosyncratic volatility computed from monthly returns}

Fama and French three-factor model has been used to find the residual returns of the size portfolios. The IV is the squared value of residuals. Thus, the following Fama-French model is used to find monthly series of returns not captured by three systematic risk factors:

$$
\begin{gathered}
R_{p t}=\alpha_{0}+\beta_{p} R_{m t}+ \\
+S_{p} S M B_{t}+h_{p} H M L_{t}+\varepsilon_{p t}, \\
I V O L_{p t}=\sqrt{\varepsilon_{p t}^{2}},
\end{gathered}
$$

where $\varepsilon_{p t}$ is the portfolio return not captured by market risk factors. If $I V O L_{p t}$ (variable to proxy for portfolio IV) cannot explain the returns of the portfolio, then IV is useless to predict stock returns. In such a case, investors do not price IV, supporting the traditional view of financial asset pricing such as CAPM where IV is considered to be not worthy to be compensated for. The regression that can be used to test the impact of IV on portfolio returns is expressed as follows:

$$
R_{p t}=\gamma_{0}+\gamma_{p} I V O L_{p t}+e_{p t} .
$$

\subsection{Expected and unexpected idiosyncratic volatility}

According to standard finance theory, IV should not be able to explain portfolio returns. However, if it explains portfolio returns, it would be interesting to know how expected and unexpected IV affect portfolio returns. In an efficient market, portfolio returns should not be influenced by expected portfolio IV because it should have been already incorporated into stock prices. If IV affects portfolio returns, it should be the unexpected part of portfolio IV. The following model can help to identify expected and unexpected IV, which then can be used to find the relationship between expected and unexpected IV and portfolio returns:

$$
\begin{aligned}
& I V O L_{p t}=\alpha_{0}+\alpha_{1} I V O L_{p t-1}+ \\
& +\alpha_{2} I V O L_{p t-2}+\varepsilon_{p t}
\end{aligned}
$$

Obviously, in the right-hand side of the equation above, $\alpha_{p}+\alpha_{1} I V O L_{p t-1}+\alpha_{2} I V O L_{p t-2}$ and $\varepsilon_{p t}$ provide the expected (EIVOL) and unexpected (UIVOL) idiosyncratic volatility for the market and size portfolios, respectively.

\subsection{Construction of sentiment variables}

If IV is not considered in the equation above, it is supposed to be captured by the error term, which ultimately becomes an important factor to determine idiosyncratic volatility. At this point, it is important to know if idiosyncratic volatility is able to explain returns when investor sentiment is accounted for.

This study considers three measures of sentiment such as moving average, TRIN and turnover. The first sentiment proxy is the ratio of the number of stocks selling above respective 4-month moving average to the number of stocks selling below respective 4-month moving average. This proxy is computed from the current price and moving average of individual stock prices. First, the study computes 4-month moving average of prices of

1 This study takes some caution to choose and clean data. Since this study involves multiple markets, visual method is also applied to confirm data integrity. There are more than 700 firms listed in the GCC stock markets. Dead firms are excluded from consideration. Thus, cleaned and reliable data are preferred over the likely existence of survivorship bias. The raw data consist of some columns of "\#ERROR", which have also been deleted. Any return over $200 \%$ in absolute value is deleted. Finally, if there is no trade for a stock for more than 24 months, it is deleted in order to avoid retention of stale information. Finally, 648 GCC firms have been selected for the study. 
every stock. In the next step, it counts the number of companies' shares those are traded above and below their own 4-month moving average prices. Then, it takes the ratio of these two and aggregate these numbers cross-section-wise to estimate the monthly stock market sentiment.

Turnover of stocks is the second sentiment proxy. Turnover of an individual stock is calculated as the number of shares of a stock traded on the last trading day of the month divided by the number of shares outstanding on the same day. Aggregate monthly market turnover can be defined as the sum of turnovers of all the individual stocks. A large firm may have more volume of trade than a small firm, but probably the former has more shares outstanding than a small one. Thus, this method accounts for such bias.

The Trading Index is typically called TRIN - the last sentiment proxy to be used in the study. To estimate TRIN, the following formula is used:

$$
\operatorname{TRIN}_{t}=\frac{D E C V O L_{t / \# D E C_{t}}}{A D V V O L_{t / \# A D V_{t}}} .
$$

Sentiment variables have the common intention of capturing markets' behavioral bias, and hence individual proxies may contain common information. This can create high correlation among independent variables (sentiment proxies), which may cause a problem in the estimation, which is commonly known as multicollinearity. Also, some of the redundant common information can be disregarded. Consequently, researchers often use tools such as principal component analysis (PCA) to estimate a single (unified) sentiment measure. Baker and Wurgler (2006) provide the procedure for using PCA to create a unified sentiment proxy. Using PCA technique, a series of unified sentiment measure from above-mentioned three sentiment proxies has been estimated for every individual market under study.

\subsection{Idiosyncratic volatility, sentiment, size and portfolio returns}

Although many studies show that IV is able to explain stock returns, it is not yet clear whether or not other factors contribute to such a relationship. As there is a huge literature (discussed above) that strongly supports the effect of sentiment on stock returns, this is a prime suspect to play a role in the IV-returns relationship. Two types of models are used to investigate the impact of sentiment and IV on stock returns: First, a model without sentiment (eq. 6) and second, a model with sentiment proxy obtained from PCA (eq. 7). These regression models can be expressed as

$$
R_{p t}=\beta_{0}+\beta_{p} E I V O L_{p t}+\delta_{p} U I V O L_{p t}+e_{p t}
$$

and

$$
\begin{aligned}
& R_{p t}=\beta_{0}+\beta_{p} E I V O L_{p t}+ \\
& +\delta_{p} \text { IIVOL }_{p t}+\theta_{p} S E N T_{t}+e_{p t},
\end{aligned}
$$

where $S E N T_{t}$ is the overall market sentiment proxy at time (month) $t$, and $E I V O L_{p t}$ and $U I V O L_{p t}$ are expected and unexpected IV, respectively.

\section{EMPIRICAL RESULTS}

Table 1 shows how IV and sentiment explain the equal weighted market portfolio returns of seven GCC markets. Four different regressions are used for each market. Market returns are regressed on IV and sentiment in the first and third regression models, respectively. Returns are regressed on expected and unexpected IV and sentiment in the second and fourth regression models, respectively. Results from the first regression suggest that Abu Dhabi, Bahrain, and Qatar markets do not consider IV to price stocks. On the other hand, Dubai, Kuwait, Oman, and Saudi Arabia markets show that these markets' returns can be significantly explained by IV. The relationship is positive for Dubai and Oman, whereas the relationship is negative for Kuwait and Saudi Arabia. The second regression divides IV into two components - expected and unexpected. For all those four countries, unexpected IV mainly explains market returns. The only exception is Oman, which shows that its returns are explained by both unexpected and expected IV. The presence of influence of expected IV on returns can be considered as a strong violation of efficiency, since such volatility is predictable and so it should have already been reflected in stock prices. Other three markets - Dubai, Kuwait, and Saudi Arabia - have also shown inef- 
ficiency as these markets are influenced by unexpected IV, although these portfolios are supposed to be well-diversified. However, these markets, at least, do not price expected IV - an indication of some efficiency.

Third and fourth regressions have introduced sentiment as it may, to some extent, explain the presence of IV for the firms. In general, sentiment is always able to explain all portfolio returns. Any positive change in the market sentiment positively increases returns. Increases in adjusted $R^{2}$ for almost all the regressions indicate the strong impact of sentiment on these markets. Interestingly, the impacts of IV on returns are not influenced that much when market sentiment is accounted for.

Table 1 has focused on the market portfolios. On the other hand, Table 2 shows if returns of size portfolios can be explained by idiosyncratic volatility

Table 1. Impact of idiosyncratic volatility and sentiment on individual market returns

\begin{tabular}{|c|c|c|c|c|c|c|c|}
\hline Market & $\begin{array}{c}\text { Constant } \\
\text { (t-stat.) }\end{array}$ & $\begin{array}{l}\text { Idio. Vol. } \\
\text { (t-stat.) }\end{array}$ & $\begin{array}{l}\text { Unexp. Idio. } \\
\text { Vol. (t-stat.) }\end{array}$ & $\begin{array}{c}\text { Exp. Idio. Vol. } \\
\text { (t-stat.) }\end{array}$ & $\begin{array}{c}\text { Unified Sent. } \\
\text { (t-stat.) }\end{array}$ & Adj. $R^{2}$ & Prob.> F-stat. \\
\hline \multirow{4}{*}{$\begin{array}{l}\text { Abu } \\
\text { Dhabi }\end{array}$} & $0.324(0.74)$ & $0.002(0.17)$ & - & - & - & 0.00 & 0.86 \\
\hline & $-2.090(-1.50)$ & - & $-0.007(-0.59)$ & $0.132(1.83)$ & - & 0.01 & 0.16 \\
\hline & $0.755(2.01)^{* *}$ & $-0.025(-2.43)^{* *}$ & - & - & $2.108(8.49)^{* * *}$ & 0.28 & 0.00 \\
\hline & $-1.634(-1.42)$ & & $-0.028(-2.76)^{* *}$ & $0.107(1.75)^{*}$ & $2.104(8.56)^{* * *}$ & 0.30 & 0.00 \\
\hline \multirow{4}{*}{ Bahrain } & $0.53(0.67)$ & $0.017(1.54)$ & - & - & - & 0.01 & 0.13 \\
\hline & $0.268(0.74)$ & - & $0.019(1.66)^{*}$ & $-0.005(-0.13)$ & - & 0.00 & 0.26 \\
\hline & $0.149(0.70)$ & $0.011(1.01)$ & - & - & $0.867(4.79)^{* * *}$ & 0.13 & 0.00 \\
\hline & $0.541(1.58)$ & & $0.015(1.37)$ & $-0.041(-1.12)$ & $0.908(5.17)^{* * *}$ & 0.13 & 0.00 \\
\hline \multirow{4}{*}{ Dubai } & $-0.017(-0.03)$ & $0.001(2.20)^{* *}$ & - & - & - & 0.02 & 0.03 \\
\hline & $1.465(1.33)$ & - & $0.011(2.59)^{* * *}$ & $-0.016(-1.07)$ & - & 0.03 & 0.02 \\
\hline & $1.104(2.43)^{* *}$ & $-0.010(-3.31)^{* * *}$ & - & - & $4.905(13.83)^{* * *}$ & 0.53 & 0.00 \\
\hline & $2.858(3.75)^{* * *}$ & - & $-0.010(-2.64)^{* * *}$ & $-0.039(-3.70)^{* * *}$ & $4.923(14.17)^{* * *}$ & 0.55 & 0.00 \\
\hline \multirow{4}{*}{ Kuwait } & $0.529(1.30)$ & $-0.039(-6.24)^{* * *}$ & - & - & - & 0.17 & 0.00 \\
\hline & $1.589(1.42)$ & - & $-0.038(-5.96)^{* * *}$ & $-0.081(-1.92)^{*}$ & - & 0.17 & 0.00 \\
\hline & $0.556(1.97)^{* *}$ & $-0.039(-9.07)^{* * *}$ & - & - & $3.084(14.15)^{* * *}$ & 0.61 & 0.00 \\
\hline & $1.459(1.90)^{*}$ & - & $-0.038(-8.71)^{* * *}$ & $-0.075(-2.64)^{* * *}$ & $3.085(14.10)^{* * *}$ & 0.61 & 0.00 \\
\hline \multirow{4}{*}{ Oman } & $0.093(0.40)$ & $0.055(3.17)^{* * *}$ & - & - & - & 0.05 & 0.00 \\
\hline & $-1.126(-2.12)^{* *}$ & - & $0.045(2.59)^{* * *}$ & $0.026(3.22)^{* * *}$ & - & 0.09 & 0.00 \\
\hline & $0.304(1.51)$ & $0.021(1.31)$ & - & - & $0.056(7.48)^{* * *}$ & 0.30 & 0.00 \\
\hline & $-0.434(-0.92)$ & - & $0.016(0.98)$ & $0.147(2.05)^{* *}$ & $1.026(7.21)^{* * *}$ & 0.31 & 0.00 \\
\hline \multirow{4}{*}{ Qatar } & $0.875(1.35)$ & $-0.03(-0.74)$ & - & - & - & 0.00 & 0.45 \\
\hline & $0.964(1.27)$ & - & $-0.002(-0.40)$ & $-0.07(0.89)$ & - & 0.00 & 0.62 \\
\hline & $1.290(2.50)^{* *}$ & $-0.012(-3.84)^{* * *}$ & - & - & $3.732(9.55)^{* * *}$ & 0.33 & 0.00 \\
\hline & $1.484(2.39)^{* *}$ & - & $-0.011(-3.14)^{* * *}$ & $-0.015(-2.39)^{* *}$ & $3.728(9.52)^{* * *}$ & 0.33 & 0.00 \\
\hline \multirow{4}{*}{ S. Arabia } & $2.067(2.63)^{* * *}$ & $-0.029(-5.00)^{* * *}$ & - & - & - & 0.12 & 0.00 \\
\hline & $0.612(0.31)$ & - & $-0.030(5.00)^{* * *}$ & $-0.007(0.25)$ & - & 0.11 & 0.00 \\
\hline & $2.029(2.85)^{* * *}$ & $-0.030(-5.57)^{* * *}$ & - & - & $3.330(6.42)^{* * *}$ & 0.28 & 0.00 \\
\hline & $1.489(0.84)$ & - & $-0.030(-5.48)^{* * *}$ & $-0.023(0.79)$ & $3.308(6.29)^{* * *}$ & 0.29 & 0.00 \\
\hline
\end{tabular}

Note: ${ }^{*},{ }^{* *}$, and ${ }^{* * *}$ indicate significance at $10 \%, 5 \%$, and $1 \%$ level, respectively. $t$-statistics are reported in parentheses. Following modified (short) version of the Fama-French model is used to capture returns not captured by systematic risk: $R_{m t}=\alpha_{0}+s_{m} S M B_{t}+h_{m} H M L_{t}+\varepsilon_{m t}$, and $I V O L_{m t}=\sqrt{\varepsilon_{m t}^{2}}$, where $\varepsilon_{m t}$ is the equal weighted market return not captured by market risk factors and $R_{m t}$ is the equal weighted return for one of the seven GCC markets. Finally, the regression that can be used to test the impact of IV on portfolio returns is expressed as follows: $R_{m t}=\gamma_{0}+\gamma_{m} I V O L_{m t}+e_{m t}$. A unified sentiment variable is added to this regression model when the impact of sentiment is addressed. The following model can help to identify expected and unexpected IV, which then can be used to find the relationship between expected and unexpected IV and market portfolio returns: $I V O L_{m t}=\alpha_{0}+\alpha_{1} I V O L_{m t-1}+\alpha_{2} I V O L_{m t-2}+\varepsilon_{m t}$. Obviously, in the right hand side of the equation above, $\alpha_{m}+\alpha_{1} I V O L_{m t-1}+\alpha_{2} I V O L_{m t-2}$ and $\varepsilon_{m t}$ provide the expected (EIVOL) and unexpected (UIVOL) idiosyncratic volatility for the size portfolios, respectively. 
for seven individual GCC stock markets. Four sizes are considered - smallest, small, large and largest. Among all the GCC markets, Abu Dhabi and Saudi Arabia show the strongest effect of IV on size portfolio returns. Interestingly, Saudi largest firm returns seem to be uninfluenced by IV. Oman, on the other hand, shows no impact of size on the IVreturns relationship. Such impact for Kuwait, Qatar, and Bahrain markets exists for largest, small, and smallest firms, respectively. Probability statistics from $F$-test also supports the fact that IV mainly influences Abu Dhabi and Saudi Arabia size portfolio returns. The impact of IV on Dubai market is only observed for small and smallest firms. This finding can be considered, at best, as a moderate effect.

The presence of IV in the Saudi market is an interesting finding, since this is the biggest and most liquid market in the GCC region with about $45 \%$ (80\% if oil giant Saudi Aramco is included) of the total regional market capitalization. This result suggests that investors in the Saudi and Abu Dhabi market cannot completely diversify unsystematic risk for portfolios made from small and smallest firms as their information is less transparent and thus investors demand reward for taking such risk. Moreover, the coefficients are positive, suggesting that firms demand higher returns when IV goes up. It may happen when investors are aware that they cannot completely diversify firm-specific risk. This phenomenon may be related to relatively small number of stocks available in these markets.

The presence of retail traders can be an important reason for the influence of IV on stock returns. Depending on circumstances, higher expected

Table 2. Impact of idiosyncratic volatility on size-portfolio returns

\begin{tabular}{|c|c|c|c|c|c|}
\hline Market & Portfolio & Constant (t-stat.) & Idio. Vol. (t-stat.) & Adj. $R^{2}$ & Prob.>F-stat. \\
\hline \multirow{4}{*}{ Abu Dhabi } & Smallest & $0.103(0.22)$ & $0.268(3.05)^{* * *}$ & 0.04 & 0.00 \\
\hline & Small & $-0.725(-1.61)$ & $0.102(4.58)^{* * *}$ & 0.10 & 0.00 \\
\hline & Large & $-0.334(-0.64)$ & $0.083(1.90)^{*}$ & 0.01 & 0.06 \\
\hline & Largest & $-0.861(-1.60)$ & $0.426(4.23)^{* * *}$ & 0.09 & 0.00 \\
\hline \multirow{4}{*}{ Bahrain } & Smallest & $-0.419(-1.05)$ & $0.387(4.66)^{* * *}$ & 0.11 & 0.00 \\
\hline & Small & $0.292(1.17)$ & $0.034(1.73)^{*}$ & 0.01 & 0.09 \\
\hline & Large & $0.029(0.08)$ & $0.038(1.47)$ & 0.01 & 0.14 \\
\hline & Largest & $-0.457(-1.08)$ & $0.103(1.17)$ & 0.00 & 0.24 \\
\hline \multirow{4}{*}{ Dubai } & Smallest & $0.039(0.07)$ & $0.176(4.63)^{* * *}$ & 0.10 & 0.01 \\
\hline & Small & $-1.012(-1.21)$ & $0.073(2.18)^{* *}$ & 0.02 & 0.03 \\
\hline & Large & $-0.240(-0.30)$ & $0.038(1.31)$ & 0.00 & 0.19 \\
\hline & Largest & $0.225(0.30)$ & $0.042(0.57)$ & 0.00 & 0.56 \\
\hline \multirow{4}{*}{ Kuwait } & Smallest & $-0.266(-0.45)$ & $0.163(1.48)$ & 0.01 & 0.14 \\
\hline & Small & $-0.685(-1.23)$ & $0.019(0.52)$ & 0.00 & 0.60 \\
\hline & Large & $-0.840(-1.59)$ & $0.014(0.44)$ & 0.00 & 0.66 \\
\hline & Largest & $-0.134(-0.29)$ & $-0.218(-2.56)^{* *}$ & 0.03 & 0.01 \\
\hline \multirow{4}{*}{ Oman } & Smallest & $0.507(1.91)^{*}$ & $0.104(1.68)^{*}$ & 0.01 & 0.09 \\
\hline & Small & $0.316(1.32)$ & $0.073(1.53)$ & 0.09 & 0.33 \\
\hline & Large & $0.240(0.67)$ & $0.014(0.70)$ & 0.00 & 0.48 \\
\hline & Largest & $0.058(0.16)$ & $0.145(1.68)^{*}$ & 0.01 & 0.09 \\
\hline \multirow{4}{*}{ Qatar } & Smallest & $0.932(1.28)$ & $-0.046(-0.56)$ & 0.00 & 0.58 \\
\hline & Small & $0.109(0.18)$ & $0.067(2.50)^{* *}$ & 0.03 & 0.01 \\
\hline & Large & $0.425(0.65)$ & $0.057(1.31)$ & 0.00 & 0.19 \\
\hline & Largest & $0.737(1.08)$ & $-0.059(-0.77)$ & 0.00 & 0.44 \\
\hline \multirow{4}{*}{ Saudi Arabia } & Smallest & $-0.557(-0.49)$ & $0.244(2.48)^{* *}$ & 0.03 & 0.01 \\
\hline & Small & $-1.360(-1.59)$ & $0.223(4.42)^{* * *}$ & 0.09 & 0.00 \\
\hline & Large & $-0.684(-0.97)$ & $0.198(3.48)^{* * *}$ & 0.06 & 0.00 \\
\hline & Largest & $-0.116(-0.18)$ & $0.037(0.65)$ & 0.00 & 0.51 \\
\hline
\end{tabular}

Note: ${ }^{*},{ }^{* *}$, and $^{* * *}$ indicate significance at $10 \%, 5 \%$, and $1 \%$ level, respectively. $t$-statistics are reported in parentheses. The following standard Fama-French model is used to capture returns not captured by systematic risk: $R_{p t}=\alpha_{0}+\beta_{p} R_{m t}+s_{p} S M B_{t}+h_{p} H M L_{t}+\varepsilon_{p t}$ and $I V O L_{p t}=\sqrt{\varepsilon_{p t}^{2}}$, where $\varepsilon_{\text {in }}$ is the portfolio return not captured by market risk factors. Portfolios are constructed based on market cap. Due to a relatively small number of firms, only four size-portfolios are considered - smallest, small, large and largest. Finally, the regression that can be used to test the impact of IV on portfolio returns is expressed as follows: $R_{p t}=\gamma_{0}+\gamma_{p} I V O L_{p t}+e_{p t}$. 
returns may lead to both increase or decrease in stock prices. In this case, stock prices go up with IV. It can happen in case of a situation where noise traders react late to a recent increase in stock prices and their strong interest drives the prices further up. In an environment of strong presence of $\mathrm{IV}$, short-selling becomes less attractive for investors to correct overpricing of high IV stocks. The positive IV-returns relationship in the GCC markets is probably the outcome of the prohibition of short-selling for most of the study period.

If results for all the markets are juxtaposed, no clear impact of size on IV-returns relationship appears. However, results are slightly in favor of the presence of the IV effect for small and smallest firms. This phenomenon implies that the investors in the GCC markets weakly consider size of firms as a reason to furnish more (or less) transparent information about firm performances. In other words, firm size has a limited role to explain IVreturns relationship.

IV can be divided into two components - expected and unexpected. Investors may behave differently with respect to expected and unexpected IV. Table 3 provides the impact of expected and unexpected IV on the size portfolio returns of individual GCC markets. Expected IV does not, in general, play a strong role to influence stock returns

Table 3. Impact of expected and unexpected idiosyncratic volatility on size-portfolio returns

\begin{tabular}{|c|c|c|c|c|c|c|}
\hline Markets & Portfolio & $\begin{array}{l}\text { Constant } \\
\text { (t-stat.) }\end{array}$ & $\begin{array}{c}\text { Unexp. Idio. Vol. } \\
\text { (t-stat.) }\end{array}$ & $\begin{array}{l}\text { Exp. Idio. Vol. } \\
\text { (t-stat.) }\end{array}$ & Adj. $R^{2}$ & Prob.>F-stat. \\
\hline \multirow{4}{*}{ Abu Dhabi } & Smallest & $-3.828(-2.36)^{* *}$ & $0.237(2.72)^{* * *}$ & $1.794(2.89)^{* * *}$ & 0.07 & 0.00 \\
\hline & Small & $-1.410(-1.26)$ & $0.100(4.46)^{* * *}$ & $0.166(1.50)$ & 0.10 & 0.00 \\
\hline & Large & $-1.719(-1.13)$ & $0.078(1.75)^{*}$ & $0.280(1.29)$ & 0.02 & 0.09 \\
\hline & Largest & $-2.714(-1.43)$ & $0.411(4.02)^{* * *}$ & $1.157(1.60)$ & 0.09 & 0.00 \\
\hline \multirow{4}{*}{ Bahrain } & Smallest & $-3.092(-1.77)^{*}$ & $0.377(4.49)^{* * *}$ & $1.484(2.10)^{* *}$ & 0.11 & 0.00 \\
\hline & Small & $0.733(0.77)$ & $0.036(1.79)^{*}$ & $-0.047(-0.29)$ & 0.01 & 0.19 \\
\hline & Large & $4.501(0.82)$ & $0.039(1.50)$ & $-0.580(-0.78)$ & 0.01 & 0.24 \\
\hline & Largest & $-2.091(-1.17)$ & $0.050(0.59)$ & $0.732(1.01)$ & 0.00 & 0.51 \\
\hline \multirow{4}{*}{ Dubai } & Smallest & $-2.231(-1.03)$ & $0.172(4.47)^{* * *}$ & $0.551(1.57)$ & 0.11 & 0.00 \\
\hline & Small & $-1.677(-0.81)$ & $0.073(2.07)^{* *}$ & $0.120(0.80)$ & 0.02 & 0.09 \\
\hline & Large & $-2.157(-1.13)$ & $0.033(1.11)$ & $0.198(1.29)$ & 0.01 & 0.12 \\
\hline & Largest & $-0.610(-0.36)$ & $0.055(0.68)$ & $0.210(0.62)$ & 0.00 & 0.65 \\
\hline \multirow{4}{*}{ Kuwait } & Smallest & $-2.617(-0.97)$ & $0.156(1.30)$ & $1.061(1.05)$ & 0.00 & 0.25 \\
\hline & Small & $-8.476(-2.67)^{* * *}$ & $-0.022(-0.61)$ & $0.162(2.35)^{* * *}$ & 0.02 & 0.05 \\
\hline & Large & $-1.737(0.68)$ & $-0.024(-3.64)^{* * *}$ & $-0.037(-1.74)^{*}$ & 0.08 & 0.00 \\
\hline & Largest & $-5.822(-2.86)^{* * *}$ & $-0.193(-2.12)^{* * *}$ & $2.006(2.62)^{* * *}$ & 0.05 & 0.00 \\
\hline \multirow{4}{*}{ Oman } & Smallest & $0.576(1.17)$ & $0.044(0.52)$ & $0.065(0.24)$ & 0.00 & 0.84 \\
\hline & Small & $0.371(0.23)$ & $0.073(1.49)$ & $0.056(0.10)$ & 0.00 & 0.32 \\
\hline & Large & $0.714(1.79)^{*}$ & $0.046(1.97)^{* *}$ & $-0.068(-1.83)^{*}$ & 0.03 & 0.03 \\
\hline & Largest & $-0.780(-1.13)$ & $0.114(0.97)$ & $0.683(1.79)^{*}$ & 0.01 & 0.13 \\
\hline \multirow{4}{*}{ Qatar } & Smallest & $0.820(0.91)$ & $-0.131(-1.32)$ & $-0.075(-0.32)$ & 0.00 & 0.40 \\
\hline & Small & $0.235(0.30)$ & $0.009(0.24)$ & $0.027(0.36)$ & 0.00 & 0.91 \\
\hline & Large & $0.905(1.00)$ & $0.080(1.67)^{*}$ & $-0.031(-0.31)$ & 0.00 & 0.24 \\
\hline & Largest & $-0.651(-0.75)$ & $-0.157(-1.72)^{*}$ & $0.435(1.96)^{* *}$ & 0.03 & 0.04 \\
\hline \multirow{4}{*}{ Saudi Arabia } & Smallest & $-0.664(-0.53)$ & $0.250(1.75)^{*}$ & $0.267(1.53)$ & 0.02 & 0.07 \\
\hline & Small & $-1.903(-1.63)$ & $0.215(3.91)^{* * *}$ & $0.0289(2.20)^{* *}$ & 0.09 & 0.00 \\
\hline & Large & $-2.022(-2.10)^{* *}$ & $0.146(2.34)^{* *}$ & $0.456(3.16)^{* * *}$ & 0.07 & 0.00 \\
\hline & Largest & $-0.055(-0.15)$ & $0.087(1.06)$ & $0.055(0.54)$ & 0.00 & 0.49 \\
\hline
\end{tabular}

Note: ${ }^{*}{ }^{* *}$, and $^{* * *}$ indicate significance at $10 \%, 5 \%$, and $1 \%$ levels, respectively.t-statistics are reported in parentheses. Thefollowing standard Fama-French model is used to capture returns not captured by systematic risk: $R_{p t}=\alpha_{0}+\beta_{p} R_{m t}+s_{p} S M B_{t}+h_{p} H M L_{t}+\varepsilon_{p t}$ and $I V O L_{p t}=\sqrt{\varepsilon_{p t}^{2}}$, where $\varepsilon_{p t}$ is the portfolio return not captured by market risk factors. Portfolios are constructed based on market cap. Due to a relatively small number of firms, only four size-portfolios are made - smallest, small, large and largest. Finally, the regression that can be used to test the impact of IV on portfolio returns is expressed as follows: $R_{p t}=\gamma_{0}+\gamma_{p} I V O L_{p t}+e_{p t}$. The following model can help to identify expected and unexpected IV, which then can be used to find the relationship between expected and unexpected IV and portfolio returns: $I V O L_{p t}=\alpha_{0}+\alpha_{1} I V O L_{p t-1}+\alpha_{2} I V O L_{p t-2}+\varepsilon_{p t}$. Obviously, in the right hand side of the equation above, $\alpha_{p}+\alpha_{1} I V O L_{p t-1}+\alpha_{2} I V O L_{p t-2}$ and $\varepsilon_{p t}$ provide the expected (EIVOL) and unexpected (UIVOL) idiosyncratic volatility for size portfolios, respectively. 
of size portfolios. Abu Dhabi, Oman, Qatar and Bahrain show weaker whereas Kuwait and Saudi Arabia show somewhat stronger impact of expected IV on returns. However, the expected IVreturns relationship cannot be related to firm size. Thus, investors in Abu Dhabi, Oman, Qatar and Bahrain are either able to satisfactorily diversify unsystematic risk or perceive the concept of such risk partially, resulting in weak compensation for expected idiosyncratic risk.

In the Saudi market, both small and large portfolio returns are influenced by both unexpected and expected IV. This finding again indicates a strong presence of retail traders in this market. Except for Kuwait, the impact of unexpected IV, if any, is always positive. The negative impact for Kuwait is a puzzle. The impact of unexpected IV on returns is not a violation of market efficiency, since it is a kind of shock to all the investors. Simply, it can be said that investors are unable to diversify their portfolio unsystematic risk with the present level of diversification.

Table 4 exhibits the results of regressions when a unified sentiment proxy is introduced along

Table 4. Impact of idiosyncratic volatility and sentiment on size-portfolio returns

\begin{tabular}{|c|c|c|c|c|c|c|}
\hline Market & Portfolio & $\begin{array}{c}\text { Constant } \\
\text { (t-stat.) }\end{array}$ & $\begin{array}{l}\text { Idio. Vol. } \\
\text { (t-stat.) }\end{array}$ & $\begin{array}{c}\text { Unified Sent. } \\
\text { (t-stat.) }\end{array}$ & Adj. $R^{2}$ & Prob.>F-stat. \\
\hline \multirow{4}{*}{ Abu Dhabi } & Smallest & $0.141(0.34)$ & $0.225(2.90)^{* * *}$ & $1.943(7.18)^{* * *}$ & 0.26 & 0.00 \\
\hline & Small & $-0.686(-1.66)^{*}$ & $0.089(4.38)^{* * *}$ & $1.616(4.38)^{* * *}$ & 0.25 & 0.00 \\
\hline & Large & $-0.351(-0.74)$ & $0.077(1.95)^{*}$ & $1.876(6.55)^{* * *}$ & 0.20 & 0.00 \\
\hline & Largest & $-0.748(-1.53)$ & $0.380(4.16)^{* * *}$ & $2.087(6.55)^{* * *}$ & 0.26 & 0.00 \\
\hline \multirow{4}{*}{ Bahrain } & Smallest & $-0.447(-1.11)$ & $0.394(4.65)^{* * *}$ & $-0.033(-0.11)$ & 0.10 & 0.00 \\
\hline & Small & $0.315(1.30)$ & $0.026(1.37)$ & $0.769(4.09)^{* * *}$ & 0.09 & 0.00 \\
\hline & Large & $-0.012(-0.03)$ & $0.024(1.52)$ & $1.388(5.06)^{* * *}$ & 0.13 & 0.00 \\
\hline & Largest & $-0.347(-0.88)$ & $0.013(0.16)$ & $1.199(4.05)^{* * *}$ & 0.08 & 0.00 \\
\hline \multirow{4}{*}{ Dubai } & Smallest & $0.536(1.03)$ & $0.086(2.42)^{* *}$ & $2.928(7.52)^{* * *}$ & 0.32 & 0.00 \\
\hline & Small & $0.333(0.50)$ & $-0.034(-1.21)$ & $5.079(11.19)^{* * *}$ & 0.42 & 0.00 \\
\hline & Large & $0.246(0.40)$ & $-0.012(-0.54)$ & $5.155(11.74)^{* * *}$ & 0.44 & 0.00 \\
\hline & Largest & $1.057(1.72)^{*}$ & $-0.101(-1.65)^{*}$ & $4.114(9.41)^{* * *}$ & 0.33 & 0.00 \\
\hline \multirow{4}{*}{ Kuwait } & Smallest & $-0.250(-0.57)$ & $0.167(2.02)^{* *}$ & $3.950(12.45)^{* * *}$ & 0.47 & 0.00 \\
\hline & Small & $-0.379(-0.81)$ & $-0.026(-0.85)$ & $3.209(9.17)^{* * *}$ & 0.32 & 0.00 \\
\hline & Large & $-0.860(-2.07)^{* *}$ & $0.020(0.80)$ & $3.331(10.42)^{* * *}$ & 0.38 & 0.00 \\
\hline & Largest & $-0.117(-0.28)$ & $-0.209(-2.64)^{* * *}$ & $1.963(6.46)^{* * *}$ & 0.21 & 0.00 \\
\hline \multirow{4}{*}{ Oman } & Smallest & $0.526(2.05)^{* *}$ & $0.093(1.57)$ & $0.642(3.62)^{* * *}$ & 0.08 & 0.00 \\
\hline & Small & $0.327(1.48)$ & $0.069(1.56)$ & $0.743(5.36)^{* * *}$ & 0.16 & 0.00 \\
\hline & Large & $0.223(0.70)$ & $0.017(0.96)$ & $1.494(6.53)^{* * *}$ & 0.20 & 0.00 \\
\hline & Largest & $0.103(0.32)$ & $0.120(1.59)$ & $1.594(7.09)^{* * *}$ & 0.24 & 0.00 \\
\hline \multirow{4}{*}{ Qatar } & Smallest & $1.169(1.95)^{*}$ & $-0.211(-2.77)^{* * *}$ & $4.020(9.04)^{* * *}$ & 0.32 & 0.00 \\
\hline & Small & $0.348(0.64)$ & $0.011(0.37)$ & $2.941(7.62)^{* * *}$ & 0.24 & 0.00 \\
\hline & Large & $0.751(1.31)$ & $-0.009(-0.24)$ & $3.076(7.61)^{* * *}$ & 0.25 & 0.00 \\
\hline & Largest & $0.890(1.47)$ & $-0.139(-1.84)^{*}$ & $3.242(7.26)^{* * *}$ & 0.22 & 0.00 \\
\hline \multirow{4}{*}{ Saudi Arabia } & Smallest & $0.127(0.12)$ & $0.067(0.68)$ & $4.522(5.31)^{* * *}$ & 0.15 & 0.00 \\
\hline & Small & $-1.054(-1.29)$ & $0.168(3.38)^{* * *}$ & $2.865(4.50)^{* * *}$ & 0.18 & 0.00 \\
\hline & Large & $-0.145(-0.21)$ & $0.086(1.45)$ & $2.579(4.68)^{* * *}$ & 0.16 & 0.00 \\
\hline & Largest & $0.211(0.33)$ & $-0.035(-0.60)$ & $2.119(4.20)^{* * *}$ & 0.18 & 0.00 \\
\hline
\end{tabular}

Note: ${ }^{*},{ }^{* *}$, and ${ }^{* * *}$ indicate significance at $10 \%, 5 \%$, and $1 \%$ levels, respectively.t-statistics are reported in parentheses. Thefollowing standard Fama-French model is used to capture returns not captured by systematic risk: $R_{p t}=\alpha_{0}+S_{p} S M B_{t}+h_{p} H M L_{t}+\varepsilon_{p t}$ and $I V O L_{p t}=\sqrt{\varepsilon_{p t}^{2}}$, where $\varepsilon_{p t}$ is the portfolio return not captured by market risk factors. Portfolios are constructed based on market cap. Due to a relatively small number of firms, only four size-portfolios are made - smallest, small, large and largest. Finally, the regression that can be used to test the impact of IV on portfolio returns is expressed as follows: $R_{p t}=\gamma_{0}+\gamma_{p} I V O L_{p t}+e_{p t}$.

The following model can help to identify expected and unexpected IV, which then can be used to find the relationship between expected and unexpected IV and portfolio returns: $I V O L_{p t}=\alpha_{0}+\alpha_{1} I V O L_{p t-1}+\alpha_{2} I V O L_{p t-2}+\varepsilon_{p t}$. Obviously, in the right hand side of the equation above, $\alpha_{p}+\alpha_{1} I V O L_{p t-1}+\alpha_{2} I V O L_{p t-2}$ and $\varepsilon_{p t}$ provide the expected (EIVOL) and unexpected (UIVOL) idiosyncratic volatility for the size portfolios, respectively. This study considers three measures of sentiment - moving average, TRIN and turnover. Using the PCA technique, a series of unified sentiment measures from multiple sentiment proxies has been estimated for each market under study. The following model is used to investigate the impact of sentiment on IV: $R_{p t}=\beta_{0}+\beta_{p} I V O L_{p t}+\theta_{p} S E N T_{t}+e_{p t}$. 
with idiosyncratic volatility in the model. This unified sentiment is created from three wellknown sentiment proxies - moving average of returns, TRIN and turnover. Adjusted $R^{2} \mathrm{~s}$ of all the models (in Table 4) have dramatically increased for every GCC market reported in Table 2. F-statistics of all the models are significant, showing that sentiment is an extremely important factor for these markets. Sharmin (2019) also reports a strong presence of sentiment in the GCC stock markets. Thus, findings of this study reiterate the fact that traditional finance theory may not be able to explain the cross-section of stock returns, and sentiment must be incorporated in the asset pricing models for these markets. The impact of size on the IV-returns relationship and sentiment-returns relationship is not strongly evidenced. That is, investors weakly take size of the firms into account while taking behavioral approach to invest. It may happen when the information quality provided by firms is not strongly related to firm size. Overall, in the presence of market sentiment, small and smaller firms are slightly more susceptible to IV.

Usually, it is believed that large firms provide better-quality information and they are followed by more institutional investors, which ultimately results in less susceptibility to market sentiment. On the other hand, investors gather information for small firms from informal sources, resulting in higher dependence on market sentiment. In the case of GCC markets, all the markets show similar dependence on sentiment as far as investment is concerned. The contemporaneous positive sentiment-returns relationship implies that a positive change in sentiment leads to a positive change in stock prices. In the presence of sentiment, investors price IV almost the similar way that has been observed in Table 2.

For Dubai and Saudi markets, investor sentiment slightly reduces the robustness of the impact of IV on stock returns, suggesting that sentiment accounts for some of the IV prevailing in these markets. Obviously, investors in these markets must consider market sentiment in taking investment decisions. When sentiment is included in the model, Abu Dhabi's IV shows significant ability to explain returns. Since sentiment is so prominent in the GCC markets, it is preferable to look into the IV-returns relationship in the presence of investor sentiment. Thus, investors are biased in their trading decisions due to the presence of sentiment and demand risk premium for taking IV as they cannot diversify their portfolio satisfactorily.

Table 5 shows the impact of expected and unexpected IV on size portfolio returns when investors' sentiment is considered in decision making. As before, sentiment positively affects returns of size portfolios across all the markets. Expected IV in Dubai and Saudi markets does not have any impact on size portfolio returns. Moreover, firm size cannot explain the impact of unexpected IV, expected IV, and sentiment on portfolio returns. Based on the results in Table 5 and Table 3, it can be said that the presence of sentiment does not clearly change the effect of unexpected IV on stock returns. When sentiment is considered, the impact of expected IV on the returns of Saudi small and large size portfolios has vanished. It suggests that sentiment has captured the effect of expected IV for the Saudi market.

The significant presence of investor sentiment in all these markets slightly reduces the impact of unexpected IV on stock returns. The presence of significant adjusted $R^{2}$ for the regressions suggests that factors that are not considered in asset pricing models - such as idiosyncratic risk and sentiment - must not be ignored.

In a nutshell, the findings of the study show that (i) idiosyncratic volatility has some impact on the risk-adjusted residual returns of the GCC size portfolios, although sentiment has a strong impact on returns, (ii) the presence of sentiment only weakly affects the influence of idiosyncratic volatility, (iii) the impacts of idiosyncratic volatility and sentiment are independent of firm size, and finally, (iv) investors are mainly influenced by unpredicted idiosyncratic volatility and predictable part of such risk are usually well-adjusted into the stock prices. 
Table 5. Impact of expected and unexpected idiosyncratic volatility and sentiment on size-portfolio returns

\begin{tabular}{|c|c|c|c|c|c|c|c|}
\hline Market & Portfolio & $\begin{array}{l}\text { Constant } \\
\text { (t-stat.) }\end{array}$ & $\begin{array}{c}\text { Unexp. Idio. Vol. } \\
\text { (t-stat.) }\end{array}$ & $\begin{array}{c}\text { Exp. Idio. Vol. } \\
\text { (t-stat.) }\end{array}$ & $\begin{array}{c}\text { Uni. Sent. } \\
\text { (t-stat.) }\end{array}$ & Adj. $R^{2}$ & $\begin{array}{l}\text { Prob.> } \\
\text { F-stat. }\end{array}$ \\
\hline \multirow{4}{*}{ Abu Dhabi } & Smallest & $-3.077(-2.14)^{* *}$ & $0.201(2.59)^{* * *}$ & $1.497(2.72)^{* * *}$ & $1.902(7.10)^{* * *}$ & 0.27 & 0.00 \\
\hline & Small & $-0.952(-0.92)$ & $0.088(4.23)^{* * *}$ & $0.117(1.15)$ & $1.612(5.92)^{* * *}$ & 0.25 & 0.00 \\
\hline & Large & $-1.064(-0.77)$ & $0.073(1.80)^{*}$ & $0.183(0.93)$ & $1.865(6.48)^{* * *}$ & 0.20 & 0.00 \\
\hline & Largest & $-1.896(-1.11)$ & $0.371(4.02)^{* * *}$ & $0.834(1.27)$ & $2.072(6.48)^{* * *}$ & 0.26 & 0.00 \\
\hline \multirow{4}{*}{ Bahrain } & Smallest & $-3.102(-1.77)^{*}$ & $0.379(4.46)^{* * *}$ & $1.488(2.10)^{* *}$ & $-0.043(-0.14)$ & 0.11 & 0.00 \\
\hline & Small & $0.894(0.98)$ & $0.027(1.44)$ & $-0.075(-0.48)$ & $0.772(4.11)^{* * *}$ & 0.09 & 0.00 \\
\hline & Large & $3.304(0.64)$ & $0.038(1.54)$ & $-0.416(-0.59)$ & $1.380(5.02)^{* * *}$ & 0.12 & 0.00 \\
\hline & Largest & $-1.831(-1.06)$ & $0.005(0.06)$ & $0.625(0.90)$ & $1.194(4.03)^{* * *}$ & 0.08 & 0.00 \\
\hline \multirow{4}{*}{ Dubai } & Smallest & $0.568(0.29)$ & $0.086(2.41)^{* *}$ & $0.081(0.26)$ & $2.923(7.40)^{* * *}$ & 0.31 & 0.00 \\
\hline & Small & $1.916(1.18)$ & $-0.029(-1.01)$ & $-0.155(-1.33)$ & $5.144(11.24)^{* * *}$ & 0.42 & 0.00 \\
\hline & Large & $-0.137(-0.09)$ & $-0.013(-0.58)$ & $0.022(0.18)$ & $5.143(11.63)^{* * *}$ & 0.43 & 0.00 \\
\hline & Largest & $2.712(1.93)^{*}$ & $-0.079(-1.17)$ & $-0.476(-1.68)^{*}$ & $4.175(9.50)^{* * *}$ & 0.34 & 0.00 \\
\hline \multirow{4}{*}{ Kuwait } & Smallest & $-1.879(-0.96)$ & $0.148(1.69)^{*}$ & $0.739(1.05)$ & $3.961(12.46)^{* * *}$ & 0.47 & 0.00 \\
\hline & Small & $-3.993(-1.38)$ & $-0.032(-1.06)$ & $0.486(1.18)$ & $3.169(8.95)^{* * *}$ & 0.33 & 0.00 \\
\hline & Large & $-1.753(-3.44)^{* * *}$ & $-0.0157(-0.55)$ & $0.163(3.04)^{* * *}$ & $3.320(10.56)^{* * *}$ & 0.40 & 0.00 \\
\hline & Largest & $-5.466(-2.98)^{* * *}$ & $-0.197(-2.40)^{* *}$ & $1.867(2.70)^{* * *}$ & $1.915(6.45)^{* * *}$ & 0.23 & 0.00 \\
\hline \multirow{4}{*}{ Oman } & Smallest & $0.689(1.45)$ & $0.043(0.53)$ & $-0.004(-0.01)$ & $0.648(3.64)^{* * *}$ & 0.06 & 0.00 \\
\hline & Small & $0.399(0.27)$ & $0.068(1.52)$ & $0.048(0.09)$ & $0.747(5.34)^{* * *}$ & 0.15 & 0.00 \\
\hline & Large & $0.741(2.11)^{* *}$ & $0.051(2.48)^{* * *}$ & $-0.071(-2.16)^{* *}$ & $1.520(6.78)^{* * *}$ & 0.25 & 0.00 \\
\hline & Largest & $-0.505(-0.84)$ & $0.112(1.08)$ & $0.516(1.54)$ & $1.580(6.98)^{* * *}$ & 0.24 & 0.00 \\
\hline \multirow{4}{*}{ Qatar } & Smallest & $1.615(2.45)^{* *}$ & $-0.011(-3.14)$ & $-0.014(-2.76)^{* * *}$ & $4.370(9.70)^{* * *}$ & 0.34 & 0.00 \\
\hline & Small & $1.184(1.48)$ & $-0.000(-0.08)$ & $-0.013(-1.20)$ & $3.032(7.56)^{* * *}$ & 0.24 & 0.00 \\
\hline & Large & $1.503(1.90)^{*}$ & $0.015(0.36)$ & $-0.117(-1.34)$ & $3.092(7.67)^{* * *}$ & 0.25 & 0.00 \\
\hline & Largest & $-0.289(-0.38)$ & $-0.213(-2.64)^{* * *}$ & $0.300(1.53)$ & $3.187(7.22)^{* * *}$ & 0.24 & 0.00 \\
\hline \multirow{4}{*}{ Saudi Arabia } & Smallest & $0.226(0.19)$ & $0.105(0.77)$ & $0.047(0.28)$ & $4.524(5.26)^{* * *}$ & 0.15 & 0.00 \\
\hline & Small & $-0.601(-0.52)$ & $0.181(3.42)^{* * *}$ & $0.093(0.70)$ & $2.929(4.40)^{* * *}$ & 0.18 & 0.00 \\
\hline & Large & $-0.519(-0.53)$ & $0.075(1.22)$ & $0.157(1.01)$ & $2.461(4.17)^{* * *}$ & 0.15 & 0.00 \\
\hline & Largest & $0.303(0.43)$ & $0.020(0.25)$ & $-0.048(-0.47)$ & $2.112(4.16)^{* * *}$ & 0.08 & 0.00 \\
\hline
\end{tabular}

Note: ${ }^{*},{ }^{* *}$, and ${ }^{* * *}$ indicate significance at $10 \%, 5 \%$, and $1 \%$ levels, respectively. $t$-statistics are reported in parentheses. The following standard Fama-French model is used to capture returns not captured by systematic risk: $R=\alpha_{0}+\beta R_{1}+S S M B_{t}+h_{p} H M L_{t}+\varepsilon_{\text {a }}$ and $I V O L_{p}=\sqrt{\varepsilon_{t}^{2}}$, where $\varepsilon_{p t}$ is the portfolio return not captured by market risk factors. Portfolios are constructed based on market cap. Due to a relatively small number of firms, only four sizeportfolios are made - smallest, small, large and largest. Finally, the regression that can be used to test the impact of IV on portfolio returns is expressed as follows: $R_{p t}=\gamma_{0}+\gamma_{p} I V O L_{p t}+e_{p t}$. The following model can help to identify expected and unexpected IV, which then can be used to find the relationship between expected and unexpected IV and portfolio returns: $I V O L_{p t}=\alpha_{0}+\alpha_{1} I V O L_{p t-1}+\alpha_{2} I V O L_{p t-2}+\varepsilon_{p t}$. Obviously, in the right hand side of the equation above, $\alpha_{p}+\alpha_{1} I V O L_{p t-1}+\alpha_{2} I V O L_{p t-2}$ and $\varepsilon_{p t}$ provide the expected (EIVOL) and unexpected (UIVOL) idiosyncratic volatility for the size portfolios, respectively. This study considers three measures of sentiment - moving average, TRIN and turnover. Using the PCA technique, a series of unified sentiment measures from multiple sentiment proxies has been estimated for each market under study. Two types of models are used to investigate the impact of sentiment on IV - first, model without sentiment and second, model with sentiment variable obtained from PCA. These regression models can be expressed as $R_{p t}=\beta_{0}+\beta_{p} E I V O L_{p t}+\delta_{p} U I V O L_{p t}+e_{p t}$ and $R_{p t}=\beta_{0}+\beta_{p} E I V O L_{p t}+\delta_{p} U I V O L_{p t}+\theta_{p} S E N T_{t}+e_{p t}$, where SENT is the overall market sentiment proxy at time (month) $t$ and $E I V O L_{p t}$ and $U I V O L_{p t}$ are expected and unexpected IV, respectively.

\section{CONCLUSION AND POLICY IMPLICATIONS}

Previous research gives strong evidence of idiosyncratic volatility and sentiment in developed and emerging markets. In this backdrop, this paper investigates the relationship between idiosyncratic volatility and the returns of the GCC stock markets in the presence of sentiment. The results of the study, to some extent, show that the GCC investors cannot diversify their portfolios to the level so that firm-specific risk becomes negligible. Moreover, the returns of four different size portfolios usually exhibit a positive relationship with contemporaneous idiosyncratic volatility. A very strong presence of senti- 
ment is also evident in these markets. Firm characteristics such as size can only impart a weak effect on the IV-returns relationship. The effect of sentiment is found to be independent of firm size. That is, markets probably do not perceive the information provided by large firms any better than that by small counterparts. The absence of a strong industry of financial advising and relatively low quality financial reporting could be the reasons for this phenomenon. Even when sentiment is considered, the effect of IV on stock returns still persists. Although market sentiment should be able to capture some idiosyncratic volatility, the findings show that such risk is largely independent of it.

This study concludes that both idiosyncratic volatility and sentiment are important risk factors and should be considered in valuation models for individual stock markets in the GCC region. Both idiosyncratic volatility and sentiment are related to the quality of relevant financial information disseminated by the market and the firms. These markets should publish a sentiment index on a daily basis, which will help both investors and regulators understand the current level of irrationality in the market. On the other hand, the presence of idiosyncratic volatility indicates that investors are unable to diversify their portfolios completely. This phenomenon may be related to lack of industries, which does not allow an investor to diversify effectively. Thus, policymakers should bring more companies to the market by offering financial stimulus such as tax breaks. Also, law may be amended so that firms with certain level of sales are compelled to go public. Finally, an investor in the GCC cannot rely solely on this market to achieve complete portfolio diversification.

\section{AUTHOR CONTRIBUTIONS}

Conceptualization: Shah Saeed Hassan Chowdhury.

Data curation: Shah Saeed Hassan Chowdhury.

Formal analysis: Shah Saeed Hassan Chowdhury.

Funding acquisition: Shah Saeed Hassan Chowdhury.

Investigation: Shah Saeed Hassan Chowdhury.

Methodology: Shah Saeed Hassan Chowdhury.

Project administration: Shah Saeed Hassan Chowdhury.

Resources: Shah Saeed Hassan Chowdhury.

Software: Shah Saeed Hassan Chowdhury.

Supervision: Shah Saeed Hassan Chowdhury.

Validation: Shah Saeed Hassan Chowdhury.

Visualization: Shah Saeed Hassan Chowdhury.

Writing - original draft: Shah Saeed Hassan Chowdhury.

Writing - review \& editing: Shah Saeed Hassan Chowdhury.

\section{REFERENCES}

1. Ali, S. M. (2016). The value premium and idiosyncratic risk: case of GCC (Master's dissertation). Kuala Lumpur: INCEIF. Retrieved from https://ikr.inceif.org/handle/ INCEIF/2371

2. Ang, A., Hodrick, R, J., Xing, Y., \& Zhang, X. (2006). The crosssection of volatility and expected returns. Journal of Finance, 51, 259-299. https://doi.org/10.1111/ j.1540-6261.2006.00836.x

3. Ang, A., Hodrick, R, J., Xing, Y., \& Zhang, X. (2009). High idiosyncratic volatility and low returns: International and further U.S. evidence. Journal of Financial Economics, 91, 1-23. https://doi. org/10.1016/j.jfineco.2007.12.005

4. Angelides, T. (2010). Idiosyncratic risk in emerging markets. Financial Review, 45, 1053-1078. Retrieved from https://econpapers.repec.org/ paper/uopwpaper/0018.htm

5. Aziz, T., \& Ansari, V. A. (2017). Idiosyncratic volatility and stock returns: Indian evidence. Cogent Economics and Finance, 5, 1-20. https://doi.org/10.1080/23322039. 2017.1420998

6. Baker, M., \& Wurgler, J. (2007). Investor sentiment in the stock market. Journal of Economic Perspectives, 21, 129-152. https://doi. org/10.1257/jep.21.2.129

7. Bali, T. G., \& Cakici, N. (2008). Idiosyncratic volatility and the cross-section of expected returns. Journal of Financial and Quantitative Analysis, 43, 29-58.

8. Barber, B. M., \& Odean, T. (2000). Trading is hazardous 
to your wealth: The common stock investment performance of individual investors. Journal of Finance, 55, 773-806. https://doi. org/10.1111/0022-1082.00226

9. Benartzi, S., \& Thaler, R. H. (2001). Naive diversification strategies in retirement saving plans. American Economic Review, 91, 79-98. Retrieved from https://www. aeaweb.org/articles?id=10.1257/ aer.91.1.79

10. Bley, J., \& Saad, M. (2012). Idiosyncratic risk and expected returns in frontier markets: Evidence from GCC. Journal of International Financial Markets, Institutions \& Money, 22, 538554. http://dx.doi.org/10.1016/j. intfin.2012.01.004

11. Boyer, M., Mitton, T., \& Vorkink, K. (2010). Expected idiosyncratic skewness. Review of Financial Studies, 23, 169-202. https://doi. org/10.1093/rfs/hhp041

12. Campbell, J. Y., Lettau, M., Malkiel, B. G., \& Xu, Y. (2001). Have individual stocks become more volatile? An empirical exploration of idiosyncratic risk. Journal of Finance, 16, 1-43. https://doi. org/10.1111/0022-1082.00318

13. Chen, Z., \& Petkova, R. (2012). Does idiosyncratic volatility proxy for risk exposure? Review of Financial Studies, 25, 2745-2787. https://doi.org/10.1093/rfs/hhs084

14. Chichernea, D. C., Ferguson, M. F., \& Kassa, H. (2015). Idiosyncratic risk, investor base and returns. Financial Management, 44, 267293. Retrieved from https:// papers.ssrn.com/sol3/papers. cfm?abstract_id=2436609

15. Chowdhury, S. S. H. (2020). Spillover of sentiments between the GCC stock markets. Global Business Review.

16. Chowdhury, S. S. H., Sharmin, R., \& Rahman, M. A. (2021). On the impact of sentiment on stock returns: The case of Dhaka Stock Exchange. Afro-Asian Journal of Finance and Accounting, 11, 392422. http://dx.doi.org/10.1504/ AAJFA.2021.10038579

17. Chua, C. T., Goh, J., \& Zhang, Z. (2010). Expected volatility, unexpected volatility and the cross-section of expected returns. Journal of Financial Research, 33, 103-123. Retrieved from https:// ideas.repec.org/a/bla/jfnres/v33y2010i2p103-123.html

18. Cotter, J., O'Sullivan, N., \& Rossi, F. (2015). The conditional pricing of systematic and idiosyncratic risk in the UK equity market. International Review of Financial Analysis, 37, 184-193. https://doi. org/10.1016/j.irfa.2014.10.002

19. Fama, E., \& French, K. (1993). Common risk factors in the returns on stocks and bonds. Journal of Financial Economics, 33, 3-53. https:// doi.org/10.1016/0304405X(93)90023-5

20. Fu, F. (2009). Idiosyncratic risk and the cross-section of expected returns. Journal of Financial Economics, 91, 24-37. https://doi. org/10.1016/j.jfineco.2008.02.003

21. Gharghori, P., See, Q., \& Veeraraghavan, M. (2011). Difference of opinion and the cross-section of equity returns: Australian evidence. Pacific-Basin Finance Journal, 19, 435-446.

22. Goetzmann, W. N., \& Kumar, A. (2008). Equity portfolio diversification. Review of Finance, 12, 433-463. https://doi. org/10.1093/rof/rfn005

23. Guo, H., \& Savickas, R. (2008). Average idiosyncratic volatility in G7 countries. Review of Financial Studies, 21, 1259-1296. https://doi. org/10.1093/rfs/hhn043

24. Kearney, C., \& Poti, V. (2008). Have European stocks become more volatile? An empirical investigation of idiosyncratic and market risk in the Euro Area. European Financial Management, 14, 419-444. http:// dx.doi.org/10.1111/j.1468036X.2007.00395.X

25. Kumari, J., Mahakund, J., \& Hiremath, G. S. (2017). Determinant of idiosyncratic volatility: Evidence from the Indian stock market. Research in International Business and Finance, $41,172-184$.

26. Li, K., Morck, R., Yang, F., \& Yeung, B. (2004). Firm-specific variation and openness in emerging markets. Review of Economics and Statistics, 86, 658669. http://dx.doi.org/10.2139/ ssrn. 462120

27. Liu, S., Kong, A., Gu, R., \& Guo, W. (2019). Does idiosyncratic volatility matter? - Evidence from Chinese stock market. Physica A: Statistical Mechanics and its Applications, 516, 393401. http://doi.org/10.1016/j. physa.2018.09.184

28. Nartea, G. V., Ward, B., \& Yao, L. (2011). Idiosyncratic volatility and cross-sectional stock returns in Southeast Asian stock markets. Accounting and Finance, 51, 10311054. http://dx.doi.org/10.1111/ j.1467-629X.2010.00384.X

29. Nartea, G. V., Wu, J., \& Liu, Z. (2013). Does idiosyncratic volatility matter in emerging markets? Evidence from China. Journal of International Financial Markets, Institutions \& Money, 27, 137-160. http://dx.doi. org/10.2139/ssrn.2311069

30. Pastor, L., \& Pietro, V. (2003). Stock valuation and learning about profitability. Journal of Finance, 58, 1749-1789. https://doi. org/10.1111/1540-6261.00587

31. Qadan, M., Kliger, D., \& Chen, N. (2019). Idiosyncratic volatility, the VIX and stock returns. North American Journal of Economics and Finance, 47, 431-441. https://doi.org/10.1016/j.najef.2018.06.003

32. Sharma, P., \& Kumar, B. (2014). Idiosyncratic Volatility and Cross-Section of Stock Returns: Evidences from India. SSRN Electronic Journal. http://dx.doi. org/10.2139/ssrn.2494736

33. Sharmin, R. (2019). Effect of sentiment on stock returns: Evidence from the Gulf Cooperation Council stock markets (unpublished $\mathrm{PhD}$ thesis). Universiti Sains Malaysia.

34. Zhong, A., \& Gray, P. (2016). The MAX effect: An exploration of risk and mispricing explanations. Journal of Banking and Finance, 65, 76-90. https://doi.org/10.1016/j. jbankfin.2016.01.007 